\title{
Osteotomy of the Spine to Correct the Spinal Deformity
}

\author{
Ki-Tack Kim*, Kyoung-Jun Park*, Jung-Hee Lee ${ }^{\dagger}$ \\ *Department of Orthopaedic Surgery, Spine Center, Kyung Hee University East West Neomedical Center, Seoul, Korea \\ ${ }^{\dagger}$ Department of Orthopaedic Surgery, Seoul Medical Center, Kyung Hee University College of Medicine, Seoul, Korea
}

\begin{abstract}
There are a number of reports on Smith-Petersen osteotomy (SPO), pedicle subtraction osteotomy (PSO) and vertebral column resection (VCR). However, there are few systematic reviews of all three kinds of osteotomies. Literature review and author's experience of SPO, PSO and VCR osteotomy will be described. Various surgical techniques can be applied according to the disease entity and magnitude of the deformity. The most appropriate methods for deformity correction should be chosen and the potential complications should be considered. Before attempting an osteotomy of the spine for a spinal deformity, sufficient surgical experience and a thorough understanding of the anatomy of the spine and adjacent structures are needed. In addition, a well-organized team with the other departments is essential.
\end{abstract}

Key Words: Spinal osteotomy, Smith-Petersen osteotomy, Pedicle subtraction osteotomy, Vertebral column resection

\section{Introduction}

In patients with a spinal deformity, the gross appearance is easily recognized. Severe spinal deformities have associated functional disability. In many cases, it is difficult to perform a normal gait. A spinal deformity can be classified mainly as a coronal deformity and sagittal deformity. A sagittal deformity has a more deformed appearance cosmetically and a higher degree of functional handicap of daily activity than a coronal deformity. A coronal deformity is characterized radiologically by the presence of scoliosis. In most cases, compensation occurs in the upper and lower mobile segments. A sagittal deformity can occur in a range of situations, such as Scheuermann's kyphosis, iatrogenic flatback, post-traumatic, neuromuscular, congenital, degenerative disorders and ankylosing spondylitis. A greater extent of the effects are exerted on the daily lives of patients with a fixed sagittal deformity due to a subjective sense of imbalance, leaning forward (stooping), early fatigue, intractable pain and difficulty of horizontal gaze ${ }^{1}$. In cases in which the deformity is not severe or flexible, the correction can be made through positioning and instrumentation. However, a spinal osteotomy is needed for correction in cases of a severe deformed, rigid and fixed deformity. The aims of an osteotomy are to restore sagittal balance so that the patient can stand erect without the need to flex the hips or knees, and to reduce the pain. The gross appearance (cosmesis) of the patients can be improved by a spinal osteotomy. This also makes it possible to perform a horizontal gaze. Functional improvement of the visceral organs can also be expected. However, most spine surgeons are burdened with the possible complications of spinal osteotomy. Accordingly, spine surgeons should seriously consider what benefits can be obtained from surgery, what types of complications can occur and what the patients can expect from the operation. In addition, an accurate understanding of the detailed anatomy and biomechanics of the spine is

Received Nov 8, 2009; 1st revised Nov 13, 2009; accepted Nov 18, 2009

Corresponding author: Kyoung Jun Park, MD

Department of Orthopaedic Surgery, Spine Center, Kyung Hee University East West Neomedical Center,

\#149, Sangil-dong, Kangdong-gu, Seoul 134-090, Korea,

Tel: +82-2-440-6291, Fax: +82-2-440-7494, E-mail: osgktnrtod@yahoo.co.kr 
also essential. Spine surgeons should acquire sufficient knowledge and surgical experience on the various types of osteotomy technique before surgery.

An osteotomy has been given a range of terms. Basically, it can be divided mainly into the following three types (Fig. 1):

1) Opening of the anterior part and closing of the posterior part are performed after removing some of the posterior structures, such as spinous process, ligamentum flavum, part of the inferior and superior articular process, using the posterior part of the annulus as a pivot (Smith-Petersen osteotomy, SPO).

2) Closing of the posterior part is performed after removing all of the posterior part, both the pedicle and half of the body using the anterior margin of the body as a pivot (pedicle subtraction osteotomy, PSO).

3 ) opening of anterior structure and closing of posterior structure are performed after the complete removal of 3 columns by placing a structure, such as a metal cage, into the middle part and then using this as a pivot. Therefore, shortening of the spinal canal is minimized and the highest degree of correction can be obtained (vertebral column resection osteotomy, VCR).

As described above, the various types of spinal osteotomy have their own indications as well as advantages/disadvantages. This paper reviews the literature on various types of spinal osteotomy and describes their surgical technique and clinical outcomes.
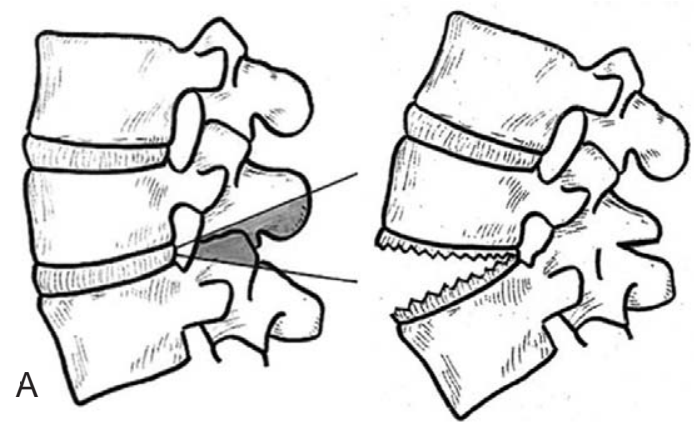

C

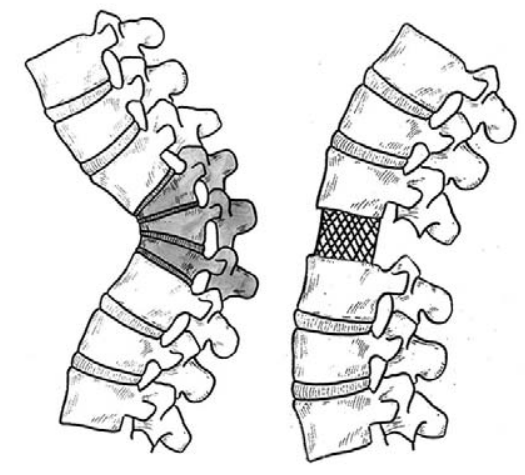

\section{Purpose of osteotomy \& pre/intra-/post- operative consideration}

The purpose of a spinal osteotomy include to enable the patient to resume a more erect posture, relieve the compression of the upper abdominal viscera by the rib margin, improve the diaphragmatic respiration and achieve horizontal vision and a good appearance.

The involvement of the hip joints in a considerable flexion deformity accentuates the sagittal imbalance of the spine. Mobilization of the hips and correction of the fixed deformity by arthroplasty should be performed before the spinal osteotomy.

Prior to a spinal osteotomy, a careful neurological examination of the patients is essential. In cases with major neurological signs, there is a higher likelihood of postoperative aggravation of the neurological symptoms. Therefore, a more careful assessment is essential for these cases. The somatosensory evoked potential, motor evoked potential, real time electro-myography and a wake-up test should be prepared to monitor any changes in the patient's neurological status at the start of the operation, during the procedure and after correction of the deformity. It can be difficult to perform endotracheal intubation in cases, such as ankylosing spondylitis, in which neck motion may be limited in a flexed position. Therefore, bronchoscopic or tracheostomic intuba-

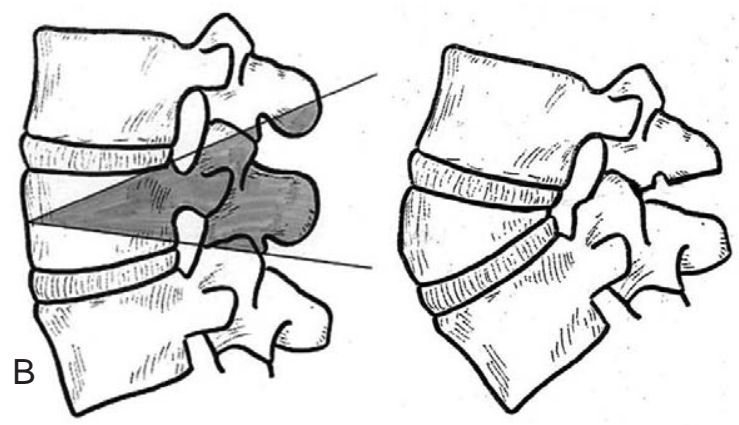

Fig. 1. Schematic diagram of the three osteotomies, showing the outline of bone to be resected. (A) Smith-Petersen osteotomy. (B) Pedicle subtraction osteotomy. (C) Vertebral column resection osteotomy. 
tion might be necessary. Accordingly, a collaborative approach with an anesthesiologist is important.

Sometimes, in cases in whom there is a severe kyphotic deformity of the spine, the hip joint also has flexion contracture. Therefore, a prone position cannot be obtained on an ordinary operating table. In these cases, operating table should be flexed to fit the patients and multiple pads should be prepared.

Occasionally, there may be situations where a table should undergo flexion or extension to achieve deformity correction. For this reason, an electrical motored table that can undergo flexion or extension should be prepared.

Rupture of the aorta or inferior vena cava is a potential complication if a correction through a large angle is attempted, particularly if the aorta has degenerative changes ${ }^{2}$. Safeguards against accidental rupture of the important vessels are needed to carry out the extension maneuver very slowly and avoid a correction through a large angle: $60^{\circ}$ is perhaps a safe margin.

If a patient with severe flexion deformity and rigid ankylosis of the cervical spine is operated upon in the prone position, considerable care is needed to ensure that the head is kept clear of the table and does not take any of the body weight. Otherwise, the neck may be fractured or dislocated when an extension force is applied to the spine.

The surgical time for a spinal osteotomy is relatively longer than other types of spine surgery. Therefore, during the procedure, a patient's head supporter might be moved, which can exert direct pressure to the eyeballs and induce an occlusion of the retinal artery, potentially leading to blindness. Therefore, eyeball protection is essential after positioning the patient. In addition, this should be confirmed by an anesthesiologist at all steps of the procedure. Sometimes, acute dilatation of the stomach, paralytic ileus or in rare cases superior mesenteric artery syndrome can occur after spinal osteotomy because an abrupt extension occurs from a flexed position. In these cases, nasogastric or rectal tube insertion may be needed during a certain period of time after surgery.

\section{Smith-Petersen osteotomy}

\section{History of SPO}

In 1945, Smith-Petersen et al. ${ }^{3}$ reported the first spinal osteotomy. It was termed a Smith-Petersen osteotomy, which has been performed by many authors. As a modification of this technique, there are procedures, such as Ponte procedure ${ }^{4}$ or polysegmental osteotomy ${ }^{5}$. Smith-Petersen et al. ${ }^{3}$ devised their spinal operation as a one-stage procedure that could be repeated at more than one level if necessary. In 1946, La Chapelle ${ }^{6}$ later achieved a similar type of correction using both a posterior and anterior approach. In La Chapelle's procedure, the ossified anterior ligaments of the spine were divided, whereas correction was achieved by manual osteoclasis in the Smith-Petersen technique. In 1959 , Herbert ${ }^{7}$ reported the results of lumbar osteotomies on 30 patients. After a wedge osteotomy of L1-2 with spinal fusion, the patient was returned to bed with the original, deformed position maintained by pillows and cushions, which were removed gradually during the course of the next two or three days, and the kyphotic deformity was corrected. A plaster jacket was then applied. In 1962, Law ${ }^{8}$ presented the largest number of patients (110 patients) operated on with corrective lumbar osteotomy for ankylosing spondylitis; of whom ten died.

At earlier times, the surgical procedure used to be performed in the lateral position due to the difficult position and a fear of a sudden correction from the prone position. There are also reports ${ }^{9}$ that it was performed under local anesthesia due to difficult endotracheal intubation. In the early stage, most studies mainly reported the correction made in patients with ankylosing spondylitis. Lethal complications, such as intraoperative death resulting from aortic rupture, paraplegia due to a spinal cord injury and nerve root injury has been reported to occur at a higher incidence $e^{2,7,8,10-12}$. For these reasons, this technique is rarely performed during a certain period of time. The reasons for the higher incidence of complications may include the sudden lengthening of the anterior part of the vertebral body and relatively narrow room for the neural structure due to the shortening of the posterior part. In addition, at that time, there was a lack of surgical instrumentations (such as pedicle screw instrumentation) that could maintain the correction. Postoperatively, a plaster jacket was used for a long time. Usually, SPO has been used for ankylosing spondylitis, however, other various types of spinal deformity can also be corrected by SPO. Meiss ${ }^{13}$ was the first author who used SPO for conditions other than ankylosing spondylitis. He performed a two-stage biplanar correction on a patient with severe kyphoscoliosis, who had been treated previously with fusion. In general, the correction can be obtained at an angle of $10-20^{\circ}$ by single $\mathrm{SPO}^{14}$. If $\mathrm{SPO}$ is performed on an ankylosing spondylitis patient, a higher 
degree of correction can be achieved, up to $30-40^{\circ}{ }^{14}$. Several modifications of SPO have been reported. For example, the Ponte procedure ${ }^{4}$ or polysegmental osteotomy ${ }^{5}$ was developed for a harmonious correction at multiple levels using the SPO technique. In 1979, Puschel and Zielke ${ }^{15}$ introduced a method based on multiple osteotomies at four to six levels. Initially, fixation was achieved using Harrington rods but they later used transpedicular screws for up to ten segments. This method gave a more overall correction from the closing wedges of the dorsal osteotomy without fracturing the anterior column, and Hehne et al. ${ }^{5}$ reported good results in 177 patients. However, in my experience, this multi-level technique in ankylosing spondylitis was not successful because in most cases, the main correction occurred at one level and it was impossible to achieve osteoclasis in some cases due to a fully ossified anterior longitudinal ligament. The latest trends are that PSO is preferred for the treatment of ankylosing spondylitis ${ }^{16}$.

\section{Indication of SPO}

The SPO is used for cases in whom a relatively small amount of correction is required. In our hospital, this procedure was performed for cases in which the correction should be performed to an angle of approximately $10-20^{\circ}$ for each level. It was also performed in cases in which the apex of the deformity is located at the thoracic spine. A long, rounded, smooth kyphosis is often an ideal candidate for multiple SPOs ${ }^{16}$. Scheuermann's kyphosis or kyphosis with a previous fusion and malunion as well as patients with a degenerative imbalance in the sagittal plane can be treated with SPO. Combined SPO at the thoracic spine and PSO at the lumbar spine can be performed in cases in whom the deformity was extended severely from the thoracic spine to the lumbar spines (Fig. 2). In addition, SPO can be used effectively in ankylosing spondylitis patients with localized kyphosis from pseudarthrosis (Andersen's lesion) ${ }^{17}$. In general, although there is a large anterior gap after SPO, there is no need for an anterior bone graft. However, in cases of pseudarthrosis, we perform anterior support with strut bone grafts. In cases in whom a coronal imbalance is associated, a coronal correction might be difficult or impossible with a SPO. Accordingly, PSO is recommended in these cases.

\section{Surgical technique of SPO}

The level chosen for the osteotomy is determined by the lowest degree of ossification anteriorly and the apex of the
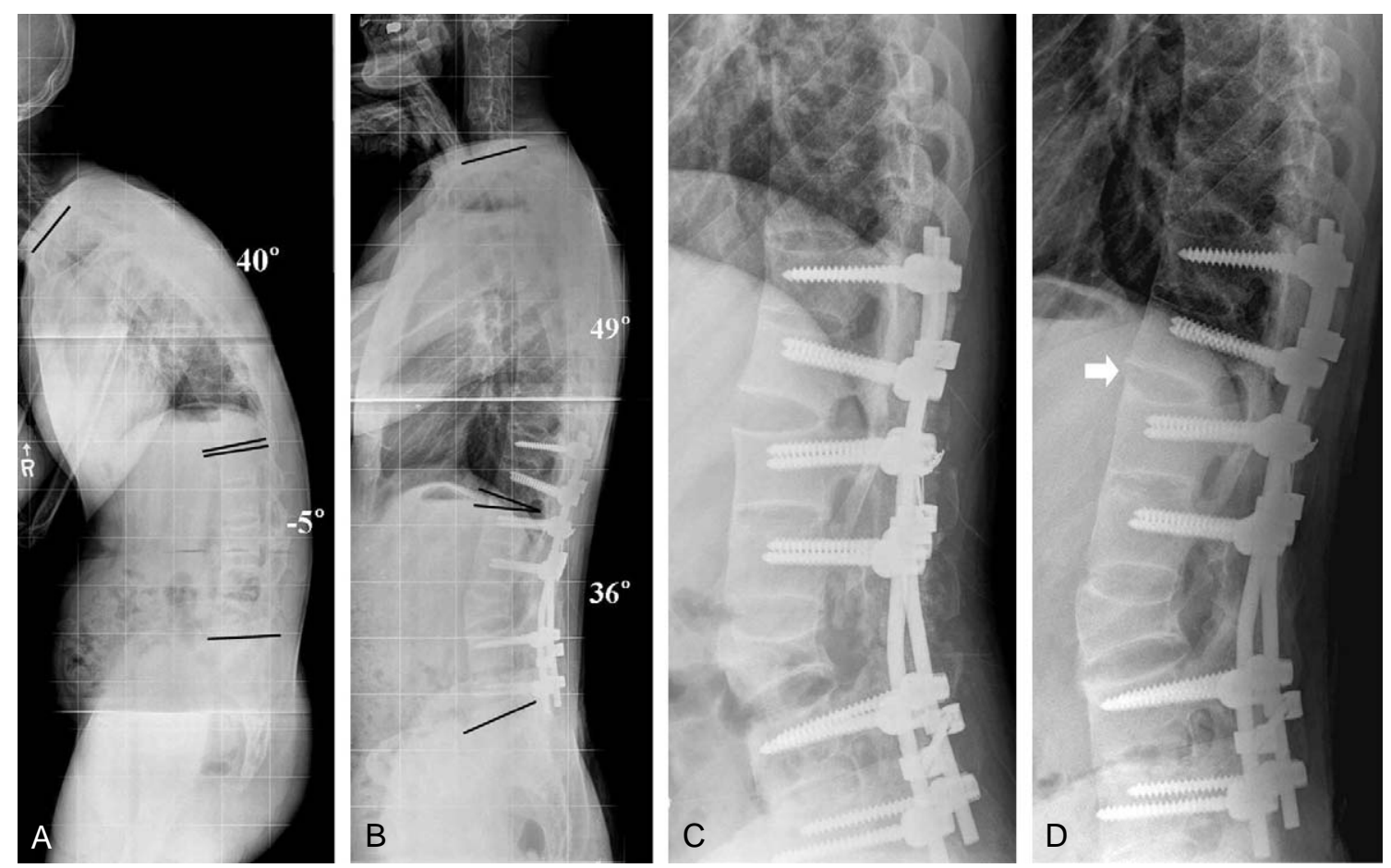

Fig. 2. A 36-year-old man with a kyphotic deformity caused by ankylosing spondylitis.

(A) Global kyphosis is caused by ankylosing spondylitis. (B) Postoperative whole spine lateral radiograph shows significant improvement of the sagittal imbalance. (C) Postoperative lateral radiograph shows SPO T12-L1 and PSO L3. (D) Note the bridging bone formation (arrow) between the anterior opening gap. 
deformity. It is preferable to remain below the level of the conus medullaris if possible.

In the prone position, the chest and iliac crests are fixed firmly with a silicone bolster and sponge pads. Using the posterior approach, the segments to be corrected are exposed both superiorly and inferiorly. Pedicle screws are inserted from the upper instrumented vertebra to the lower instrumented vertebra. The initial resection is performed on the spinous process at the level to be resected. Portions of the spinous processes above and below should also be removed. In the area to be resected, lamina and facet joints are removed completely using an osteotome or Kerrison rongeur in an oblique manner. A gutter is formed as a $\mathrm{V}$ shape from the center bilaterally to the oblique directions on the upward and lateral side. In particular, on the lateral end, the structure between the upper and lower pedicles should be removed completely to prevent nerve root impingement. Commonly, the width of the gutter should be $10-15 \mathrm{~mm}$. After the gutter is completed, it is closed posteriorly by manual compression and a push down force with a compression device on both-sides or extending the operation table. Special care should be taken to undercut the margin of osteotomized lamina in order to avoid neural compression during closure. The rods are then set and decortication with an autogenous morsellized bone graft is applied over the entire levels of the corrected segments.

\section{Clinical outcomes of SPO (Table 1)}

In 1962, Law $^{8}$ published his results in treating 120 ankylosing spondylitis patients with SPO. The deformity correction achieved ranged from $25^{\circ}$ to $45^{\circ}$. There were 10 perioperative deaths. In 1977, Simmons ${ }^{9}$ performed a SPO on a patient in the lateral position using local anesthesia and achieved an average correction of $47^{\circ}$ with no complications reported. In 1985, McMaster $^{22}$ described the use of modified Harrington compression instrumentation with SPO. He obtained an average correction of $38^{\circ}$. The complications included three dural tears and two instances of ileus. In 1990, Hehne et al. ${ }^{5}$ assessed 177 patients treated with polysegmental osteotomies and pedicle screw fixation. They reported an average correction of $10^{\circ}$ per osteotomy. The complications included 4 deaths, 4 permanent root injuries, 19 resolved neurological deficits, 4 implant failures,and 6 deep wound infections. The term 'flatback syndrome' was popularized by Lagrone et al. ${ }^{23}$ They performed 66 osteotomies with 19 concomitant anterior procedures to treat flatback syndrome. There were 33 complications, with

Table 1. Literature review on Smith-Petersen osteotomy

\begin{tabular}{|c|c|c|c|c|c|c|}
\hline Author (year) & $\begin{array}{l}\text { Patients } \\
\text { (n) }\end{array}$ & $\begin{array}{l}\text { Causes of } \\
\text { deformity }\end{array}$ & $\begin{array}{l}\text { Correction } \\
\left({ }^{\circ}\right)\end{array}$ & $\begin{array}{c}\text { Neurologic } \\
\text { complications (n) }\end{array}$ & $\begin{array}{c}\text { Other Major } \\
\text { Complications (n) }\end{array}$ & Mortality \\
\hline Smith-Petersen $(1945)^{3}$ & 6 & AS & NM & - & - & - \\
\hline Herbert $(1959)^{7}$ & 50 & $\begin{array}{c}\text { AS (48) } \\
\text { Others (2) }\end{array}$ & NM & 3 (1 died) & 12 (3 death) & $\begin{array}{l}1 \text { cord compression } \\
1 \text { pulmonary abscess } \\
2 \text { cardiac failure }\end{array}$ \\
\hline $\operatorname{McMaster}(1962)^{10}$ & 15 & AS & $40-60$ & 1 (paraplegia) & 2 (1 death) & 1 cerebral anoxia \\
\hline Goel $(1968)^{11}$ & 15 & $\begin{array}{l}\text { AS (11) } \\
\text { Others (4) }\end{array}$ & 37 & 2 (resolved) & 2 & - \\
\hline Law $(1962)^{8}$ & 120 & AS & $\begin{array}{c}25-45 \\
(110 \text { lumbar) } \\
20-30 \\
\text { (10 cervical) }\end{array}$ & 9 (3 died $)$ & 8 (7 died) & $\begin{array}{l}3 \text { cord injury } \\
3 \text { cortisone shock } \\
4 \text { others }\end{array}$ \\
\hline Simmons $(1977)^{9}$ & 19 & AS & 47 & - & - & - \\
\hline Styblo $(1985)^{18}$ & 20 & AS & 44 & & 7 & - \\
\hline Camargo $(1986)^{2}$ & 66 & AS & $22-55$ & 2 (resolved) & 1 (1 death) & 1 aortic rupture \\
\hline Bradford (1987) ${ }^{19}$ & 21 & AS & 27.6 & 2 (resolved) & 4 & - \\
\hline Weale $(1995)^{12}$ & 50 & AS & 38.7 & 7 (6 resolved) & 14 (2 death) & $\begin{array}{l}1 \text { sepsis } \\
1 \text { uncontrolled hemorrhage }\end{array}$ \\
\hline Lazennec $(1997)^{20}$ & 19 & AS & 41 & 7 & 12 & - \\
\hline Chang $(2006)^{21}$ & 30 & AS & 38 & - & 2 & - \\
\hline $\operatorname{Kim}(2007)^{17}$ & 12 & AS & 20.9 & 2 (resolved) & 4 & - \\
\hline
\end{tabular}

AS: Ankylosing spondylitis, NM: not mentioned. 
no death or patients with permanent neurologic deficits. Recently, Voos et al. ${ }^{24}$ reported on 27 patients with a rigid deformity treated with multiple osteotomies. The average sagittal balance was corrected by $6.5 \mathrm{~cm}$. Nine complications were encountered (three pseudarthroses, five implant failures, and one transient neurologic deficit)

\section{Pedicle subtraction osteotomy}

\section{History of PSO}

In the literature, there are several reports on closing wedge osteotomy. In 1963, Scudese ${ }^{25}$ first described a vertebral wedge osteotomy for the correction of lumbar kyphosis in a patient with ankylosing spondylitis. He removed the back part of the upper surface of the body of L3. Wedging of the disc space and body of L3 with posterior narrowing was then done. Jaffray et al. ${ }^{26}$ reported another closing wedge osteotomy with transpedicular fixation in three ankylosing spondylitis patients. He excised a posterior wedge based on the pedicle on the 2 nd lumbar vertebra or 4th lumbar vertebra and recommended that the pedicles should be preserved to protect the nerve roots during closure of the osteotomy. On the other hand, a transpedicular wedge resection osteotomy was described by Thomasen ${ }^{27}$ to correct deformities secondary to ankylosing spondylitis in 1985 . He performed corrective osteotomies on the 2nd lumbar vertebra in eleven patients. There were no fatal complications. However, one patient had a horizontal fracture of L2 with a dislocation of the upper part of the vertebra with pressure on the cauda equina. After repositioning the upper dislocated part of the vertebral body, the patient achieved total regeneration of the nerve function after one year. A pedicle subtraction osteotomy has the advantages of obtaining a correction through three columns from the posterior approach without lengthening the anterior column, thereby maximizing the healing potential while avoiding stretching the major vessels and viscera anterior to the spine ${ }^{28}$. A substantial amount of blood loss is one of the disadvantages of $\mathrm{PSO}^{16}$. However, correction can be obtained with an average angle of $30-40^{\circ}$ at a single segment. In our series, the maximum correction angle obtained at a single segment was $60^{\circ}$. In recent years, PSO has been performed increasingly to treat deformities other than ankylosing spondylitis, such as iatrogenic fixed sagittal imbalance ${ }^{1,16}$. The term "eggshell decancellation" was first described by Heinig and Chewning $^{29}$. At present, it is used in conjunction with PSO, such as a posterior shortening osteotomy.

\section{Indications of PSO}

This procedure is commonly used for cases in whom the correction should be performed at an angle of approximately $30^{\circ}$, which is performed mainly at the lumbar level. The ideal candidates for PSO are those patients with a substantial sagittal imbalance of $>10$ to $12 \mathrm{~cm}$, those patients with a sharp, angular kyphosis, and those patients who have circumferential fusion between multiple segments ${ }^{16}$. In addition, PSO can also be used effectively in most ankylosing spondylitis patients. PSO can also be performed at the thoracic spine. However, to avoid cord injury, it is generally performed at below L1. It can also be performed to easily correct the coronal imbalance in cases with moderate kyphoscoliosis.

\section{Surgical techniques of PSO}

After general endotracheal anesthesia, the patients are placed in the prone position on an operating table, which is flexed in the reverse $\mathrm{V}$ shape. A subperiosteal dissection is carried out to exposure the posterior elements as far laterally as the transverse processes. Pedicle screws are inserted into two or three segments above and below the pedicles to be resected. After identifying both pedicles to be resected, holes are made through the pedicles into the vertebral body. Curettes are used to increase the size of the pedicle holes. The transverse processes are excised at their bases. Using angled curettes, the cancellous bone in the body is pushed anteriorly into the body to create a cavity in the vertebrae. A laminectomy and facetectomy are performed. The posterior and lateral part of the body is decancellized with angled curettes and both pedicles are enucleated with a small osteotome. After thinning the posterior and lateral cortical walls with curettes, the posterior cortex of vertebral body is pushed down into the body. With firm grasping of the cranial and caudal spinous processes with towel clamps, the operating table is extended, gradually closing the osteotomy. Pedicle screw stabilization is performed after confirming that the exiting nerve roots are free. The spinal cord function is monitored continuously by the motor-evoked potentials. 


\section{Clinical outcomes of PSO (Table 2)}

The pedicle subtraction osteotomy is advantageous in that it can produce substantial correction at a single level, results in successful bone union due to bone contact of three columns, and can be performed without the use of a supplemental anterior approach. In 2001, Berven et al. ${ }^{1}$ reported a 57-month follow-up on 13 consecutive patients treated with PSO for the treatment of a fixed sagittal plane deformity. The measurement of the $\mathrm{C} 7$ plumb line to sacrum improved $63 \%$ at the last follow-up and lumbar lordosis increased from $15.5^{\circ}$ to $-45.4^{\circ}$. There were 3 dural tears, 4 transient paresis, and 1 adjacent segment kyphosis. However, the level of patient satisfaction was high in all patients. In 2002, the authors ${ }^{33}$ reported the results of pedicle subtraction osteotomies on 45 ankylosing spondylitis patients. In our series, the postoperative complications consisted of paralytic ileus in five patients, monocular visual disturbances in two patients (one permanent), and neurological deficits in five patients (four transient radiculopathy). However, most patients revealed good correction and clinical results. Bridwell et al. ${ }^{28}$ reported that the average increase in lordosis and improvement in the sagittal plumb line was $34.1^{\circ}$ and $13.5 \mathrm{~cm}$, respectively. In 2006, Boachie-Adjei et al. ${ }^{35}$ reported a modification of the pedicle subtraction osteotomy for the correction of a fixed sagittal imbalance. In their series, the lumbar lordosis improved an average of $13^{\circ}$ to $53^{\circ}$ and the sagittal vertical axis demonstrated a preoperative sagittal decompensation averaging $11.3 \mathrm{~cm}$ with a correction to $2.4 \mathrm{~cm}$. Kim et al. ${ }^{41}$ analyzed their results retrospectively at a minimum of five years after PSO in thirty-five patients.
Between two and five years postoperatively, the authors did not observe any significant radiographic changes in thoracic kyphosis and lumbar lordosis. Although eight patients subsequently underwent revision procedures for the treatment of pseudarthrosis, the authors concluded that PSO can provide satisfactory clinical and radiographic outcomes at a minimum of five years postoperatively.

\section{Vertebral column resection}

\section{History of VCR}

In a rigid deformity with decompensation, translation of the spinal column is essential for restoring the trunk balance and correcting the deformity. In these cases, VCR is the only option. VCR was first described in 1922 by MacLen$\operatorname{nan}^{42}$, who performed an apical resection from a posterioronly approach with postoperative casting for the treatment of severe scoliosis. VCR represents the complete removal of more than one vertebral segment. It was previously used for cases, such as spinal column tumor, spondyloptosis, congenital kyphosis, congenital scoliosis including a hemivertebrae excision ${ }^{43,44}$. In 1983, Luque ${ }^{45}$ presented eight cases of vertebrectomy in patients with a primary spinal deformity $>90^{\circ}$. These patients underwent an anterior and posterior vertebrectomy. In 1987, a modification of the Luque technique was described by Bradford ${ }^{46}$. He presented 16 patients, all of whom underwent an anterior and posterior vertebral column resection and arthrodesis for fixed multiplanar deformities. In 2002, Suk et al. ${ }^{47}$ developed the pos-

Table 2. Literature review on Pedicle subtraction osteotomy

\begin{tabular}{|c|c|c|c|c|}
\hline Author (year) & Patients (n) & Correction $\left({ }^{\circ}\right)$ & Neurologic complications (n) & Other major complications (n) \\
\hline Thomasen $(1985)^{27}$ & 11 & 28 & 1 (transient) & - \\
\hline Thiranont $(1993)^{30}$ & 6 & 33 & - & 1 \\
\hline Chen $(2001)^{31}$ & 78 & 34.5 & 1 (transient) & 10 \\
\hline Berven $(2001)^{1}$ & 13 & 29.9 & 4 (transient) & 5 \\
\hline Murrey $(2002)^{32}$ & 59 & 26 & 2 & 8 \\
\hline $\operatorname{Kim}(2002)^{33}$ & 45 & 34 & 5 & 2 \\
\hline Bridwell $(2003)^{28}$ & 27 & 34.1 & 1 & 13 \\
\hline Cho $(2005)^{34}$ & 41 & 31.7 & 3 & 12 \\
\hline Boachie-Adjei (2006) ${ }^{35}$ & 24 & 40 & 2 & 12 \\
\hline Yang $(2006)^{36}$ & 35 & 24.6 & 3 & 5 (1 died $)$ \\
\hline Buchowski $(2007)^{37}$ & 108 & 32.2 & 12 & \\
\hline Ikenaga $(2007)^{38}$ & 67 & & 5 & 22 \\
\hline Mummaneni $(2008)^{39}$ & 10 & & 1 & 10 \\
\hline Kiaer $(2009)^{40}$ & 36 & 45 & 1 & 6 \\
\hline
\end{tabular}


terior-only approach for VCR (PVCR) in an attempt to reduce the operation time and complications from lengthy combined anterior-posterior procedures.

\section{Indications of VCR}

VCR is usually recommended in cases in whom a substantial amount of correction is needed, which cannot be obtained easily by PSO. The indications of VCR involve fixed trunk translation, severe scoliosis (congenital scoliosis or neuromuscular scoliosis), spinal tumor, spondyloptosis, rigid spinal deformities $>80^{\circ}$ in the coronal plane, and asymmetry between the length of the convex column and concave column of the deformity, which preclude the achievement of balance by a simple osteotomy alone ${ }^{48}$.

\section{Surgical technique of VCR}

The number of vertebral bodies to be resected depends on the magnitude of curvature. Curves with a sharp angle might be best corrected by a resection of a single vertebral body, whereas curves that are broad and sweeping may require a resection of multiple vertebral bodies at the apex to minimize stretching of the neural elements.

VCR can be performed either through a combined anterior and posterior approach or through a posterior approach only. This paper describes the procedure through the posterior approach only. The patient is placed prone on a fourposter frame. First, the segments to be operated are exposed subperiosteally as laterally as possible through posterior approach. Pedicle screws are placed segmentally, except for the resected segments. Complete exposure should be done to both transverse processes to allow easier removal of the vertebral bodies. If the segments to be resected are located on the thoracic spine, costotransversectomies should be performed to exposure the vertebral body. Complete removal of the posterior components (spinous processes, lamina and facet joints) should be performed to as the level of the segments that need to be removed. Both pedicles are then removed using an osteotome. During this procedure, the nerve roots should be saved in lumbar spine. However, in thoracic spine, the nerve roots can be sacrificed because those are intercostal nerves. The dissection should be performed in such a manner that the epidural vessels that are in close contact with the pedicles and vertebral body should not be ruptured. This is one of the tips that are essential for preventing massive bleeding. If epidural vessels are injured, the bleeding should be controlled by electric cauterization and/or hemostatic agents such as surgicel, gelfoam, and cottonoid. Osteotomy of vertebral body is performed on either side of thecal sac. Bone resection should be wedged in sagittal plane and may be asymmetric or symmetric in coronal plane to correct kyphosis and also scoliosis component. The bone should be removed completely to ensure that anterior cortical breakage should occur. Before procedure for the contralateral side, fixation should be performed using a temporary rod. The same procedure should then be performed for the contralateral side. In this technique, the vertebral body is removed completely, making a large defect, and there is a lack of bone-on-bone contact. Accordingly, a structural autograft or structural allograft or metal cage should be used for a reconstruction. Using the middle column as a hinge, the anterior part undergoes slight lengthening and the posterior part undergoes shortening to obtain the largest possible amount of correction. It is also import to minimize the changes in the length of the middle column at the cord level. Once a deformity correction is complete, connecting between the pedicle screws and rods is performed. To avoid nonunion or pseudarthrosis, we try to minimize the extent of bony defect by bone-on-bone contact. However, in cases of inevitable bony defect, it is covered with thin rectangular shape autologous bone graft. Then, abundant morsellized bone graft is applied after decortications with a gouge or burr.

\section{Clinical outcomes of VCR (Table 3)}

Boachie-Adjei and Bradford ${ }^{43}$ performed a two-stage VCR in 16 patients with severe rigid spine deformities. The final scoliosis correction averaged $43 \%$ and physiological sagittal alignment was achieved in all patients. However, complications were encountered in seven patients (43\%). They concluded that the concept of decancellation, radical vertebral column resection, spinal shortening, and segmental instrumentation posteriorly can achieve a balanced correction as well as significant pain relief for the certain patient who present with severe rigid spine deformity that cannot be treated adequately using more established techniques. Bradford and Tribus ${ }^{48}$ reported that the coronal and sagittal decompensation were corrected by an average of $82 \%$ and $87 \%$. Although complications occurred in $58 \%$ of their patients, all patients rated their results as either good or excellent at the follow up examination. The authors concluded that the complications are transient, and the benefits 
Table 3. Literature review on vertebral column resection osteotomy

\begin{tabular}{|c|c|c|c|c|c|c|}
\hline \multirow{2}{*}{ Author (year) } & \multirow{2}{*}{$\begin{array}{l}\text { Patients } \\
\text { (n) }\end{array}$} & \multirow{2}{*}{ Disease Entity (n) } & \multicolumn{2}{|c|}{ Correction $\left({ }^{\circ}\right)$} & \multicolumn{2}{|c|}{ Major complications (n) } \\
\hline & & & Coronal & Sagittal & Neurologic & Others \\
\hline Boachie-Adjei $(1991)^{43}$ & 16 & Variable & 46 & 25 & 1 (transient) & 6 \\
\hline Bradford $(1997)^{48}$ & 24 & Variable & 54 & 30 & 3 (transient) & 11 \\
\hline \multirow[t]{3}{*}{ Suk $(2002)^{47}$} & 70 & Adult scoliosis & 57 & & 12 (2 permanent $)$ & 12 \\
\hline & & Congenital kyphoscoliosis & 35 & 40 & & \\
\hline & & Postinfectious kyphosis & & 53 & & \\
\hline Suk $(2005)^{49}$ & 25 & Fixed lumbosacral deformity & 23 & 40 & 2 (transient) & 3 \\
\hline Suk $(2005)^{50}$ & 16 & Severe rigid scoliosis & 63.4 & & 2 (1 permanent) & 2 \\
\hline \multirow[t]{5}{*}{ Lenke $(2009)^{51}$} & 35 & Scoliosis & 61 & & 4 & 8 \\
\hline & & Global kyphosis & & 56 & & \\
\hline & & Angular kyphosis & & 51 & & \\
\hline & & Kyphoscoliosis & 52 & 47 & & \\
\hline & & Congenital scoliosis & 24 & & & \\
\hline
\end{tabular}

in this select group of patients outweighed the risks. Suk et al. ${ }^{47}$ retrospectively analyzed their results of 70 patients with severe spinal deformities at a minimum of two years after a posterior vertebral column resection. The sagittal curves were reduced on average from $111^{\circ}$ preoperatively to $50^{\circ}$ postoperatively in patients with adult scoliosis and from $68^{\circ}$ preoperatively to $12^{\circ}$ postoperatively in those with postinfectious kyphosis. In another study by Suk et al. ${ }^{49}$, twentyfive patients with a lumbosacral deformity were treated with a vertebral column resection by removing more than two vertebrae on average. The patients obtained approximately $60 \%$ correction of the coronal deformity and $40^{\circ}$ correction of the kyphosis. Suk et al. ${ }^{47}$ evaluated retrospectively the complication rate after a vertebral column resection in 70 patients with severe spinal deformities. Complications were encountered in 24 patients (34\%): 2 complete cord injuries in severe adult scoliosis and thoracic kyphosis, 6 hematomas, 4 root injuries, 5 fixation failures, 2 infections, and 5 hemopneumothoraxes. In another study by Suk et al. ${ }^{49}$, they reported a mean blood loss of 2,810 ml (range, 320 to $5,460 \mathrm{ml}$ ), indicating that substantial blood loss can occur with this procedure.

\section{Conclusions}

With the advancement of anesthetic techniques, surgical techniques and intraoperative neurophysiological monitoring, deformities that have previously been contraindicated can now be corrected using a range of surgical techniques.

However, prior to operation, a thorough understanding of the anatomy of the adjacent structures, such as the neural structure, visceral structure, and spinal column, as well as sufficient surgical technique are essential. In addition, consideration of the myriad of potential complication that might occur is important. Therefore, well-organized teamwork with other departments including the anesthesiology, internal medicine, neurology and rehabilitation is indispensable.

\section{REFERENCES}

1. Berven SH, Deviren V, Smith JA, et al: Management of fixed sagittal plane deformity: results of the transpedicular wedge resection osteotomy. Spine (Phila Pa 1976) 2001; 26: 2036-2043.

2. Camargo FP, Cordeiro EN, Napoli MM: Corrective osteotomy of the spine in ankylosing spondylitis. Experience with 66 cases. Clin Orthop Relat Res 1986; (208): 157-167.

3. Smith-Petersen MN, Larson CB, Aufranc OE: Osteotomy of the spine for correction of flexion deformity in rheumatoid arthritis. Clin Orthop Relat Res 1969; (66): 6-9.

4. Geck MJ, Macagno A, Ponte A, Shufflebarger HL: The Ponte procedure: posterior only treatment of Scheuermann's kyphosis using segmental posterior shortening and pedicle screw instrumentation. J Spinal Disord Tech 2007; 20: $586-593$

5. Hehne HJ, Zielke K, Bohm H: Polysegmental lumbar osteotomies and transpedicled fixation for correction of long-curved kyphotic deformities in ankylosing spondylitis. Report on 177 cases. Clin Orthop Relat Res 1990; (258): 49-55. 
6. La Chapelle EH: Osteotomy of the lumbar spine for correction of kyphosis in a case of ankylosing spondylitis. J Bone Joint Surg Am 1946; 28: 851-858.

7. Herbert JJ: Vertebral osteotomy for kyphosis, especially in Marie-Strumpell arthritis: a report on fifty cases. J Bone Joint Surg Am 1959; 41: 291-302.

8. Law WA: Osteotomy of the spine. J Bone Joint Surg Am 1962; 44: 1199-1206.

9. Simmons EH: Kyphotic deformity of the spine in ankylosing spondylitis. Clin Orthop Relat Res 1977; (128): 65-77.

10. McMaster PE: Osteotomy of the spine for fixed flexion deformity. Pac Med Surg 1965; 73: 314-316.

11. Goel MK: Vertebral osteotomy for correction of fixed flexion deformity of the spine. J Bone Joint Surg Am 1968; 50: 287-294.

12. Weale AE, Marsh CH, Yeoman PM: Secure fixation of lumbar osteotomy. Surgical experience with 50 patients. Clin Orthop Relat Res 1995; (321): 216-222.

13. Meiss WC: Spinal osteotomy following fusion for paralytic scoliosis. J Bone Joint Surg Am 1955; 37: 73-77.

14. Burton DC: Smith-Petersen osteotomy of the spine. Instr Course Lect 2006; 55: 577-582.

15. Puschel J, Zielke K: Korrekturoperation bei BechterewKyphose. Indikation, Technik, Ergebnisse. Z Orthop 1982; 120: 338 .

16. Bridwell KH: Decision making regarding Smith-Petersen vs. pedicle subtraction osteotomy vs. vertebral column resection for spinal deformity. Spine (Phila Pa 1976) 2006; 31: S171- S178.

17. Kim KT, Lee SH, Suk KS, Lee JH, Im YJ: Spinal pseudarthrosis in advanced ankylosing spondylitis with sagittal plane deformity: clinical characteristics and outcome analysis. Spine (Phila Pa 1976) 2007; 32: 1641-1647.

18. Styblo K, Bossers GT, Slot GH: Osteotomy for kyphosis in ankylosing spondylitis. Acta Orthop Scand 1985; 56: 294-297.

19. Bradford DS, Schumacher WL, Lonstein JE, Winter RB: Ankylosing spondylitis: experience in surgical management of 21 patients. Spine (Phila Pa 1976) 1987; 12: 238-243.

20. Lazennec JY, Saillant G, Saidi K, et al: Surgery of the deformities in ankylosing spondylitis: our experience of lumbar osteotomies in 31 patients. Eur Spine J 1997; 6: 222-232.

21. Chang KW, Tu MY, Huang HH, et al: Posterior correction and fixation without anterior fusion for pseudoarthrosis with kyphotic deformity in ankylosing spondylitis.
Spine (Phila Pa 1976) 2006; 31: E408- E413.

22. McMaster MJ: A technique for lumbar spinal osteotomy in ankylosing spondylitis. J Bone Joint Surg Br 1985; 67: 204-210

23. Lagrone MO, Bradford DS, Moe JH, et al: Treatment of symptomatic flatback after spinal fusion. J Bone Joint Surg Am 1988; 70: 569-580.

24. Voos K, Boachie-Adjei O, Rawlins BA: Multiple vertebral osteotomies in the treatment of rigid adult spine deformities. Spine (Phila Pa 1976) 2001; 26: 526-533.

25. Scudese VA, Calabro JJ: Vertebral wedge osteotomy: correction of rheumatoid (Ankylosing) spondylitis. JAMA 1963; 186: 627-631.

26. Jaffray D, Becker V, Eisenstein S: Closing wedge osteotomy with transpedicular fixation in ankylosing spondylitis. Clin Orthop Relat Res 1992; (279): 122-126.

27. Thomasen E: Vertebral osteotomy for correction of kyphosis in ankylosing spondylitis. Clin Orthop Relat Res 1985; (194): 142-152.

28. Bridwell KH, Lewis SJ, Lenke LG, Baldus C, Blanke K: Pedicle subtraction osteotomy for the treatment of fixed sagittal imbalance. J Bone Joint Surg Am 2003; 85: 454463.

29. Hening CF, Chewning SJ Jr: Eggshell procedure. (in Bradford DS ed. Master techniques in orthopaedic surgery: The spine, 1st ed. Philadelphia, Lippincott Williams \& Wilkins: 199, 1996).

30. Thiranont N, Netrawichien P: Transpedicular decancellation closed wedge vertebral osteotomy for treatment of fixed flexion deformity of spine in ankylosing spondylitis. Spine (Phila Pa 1976) 1993; 18: 2517-2522.

31. Chen IH, Chien JT, Yu TC: Transpedicular wedge osteotomy for correction of thoracolumbar kyphosis in ankylosing spondylitis: experience with 78 patients. Spine (Phila Pa 1976) 2001; 26: E354- E360.

32. Murrey DB, Brigham CD, Kiebzak GM, Finger F, Chewning SJ: Transpedicular decompression and pedicle subtraction osteotomy (eggshell procedure): a retrospective review of 59 patients. Spine (Phila Pa 1976) 2002; 27: 2338-2345.

33. Kim KT, Suk KS, Cho YJ, Hong GP, Park BJ: Clinical outcome results of pedicle subtraction osteotomy in ankylosing spondylitis with kyphotic deformity. Spine (Phila Pa 1976) 2002; 27: 612-618.

34. Cho KJ, Bridwell KH, Lenke LG, Berra A, Baldus C: Comparison of Smith-Petersen versus pedicle subtraction osteotomy for the correction of fixed sagittal imbalance. 
Spine (Phila Pa 1976) 2005; 30: 2030-2037.

35. Boachie-Adjei O, Ferguson JA, Pigeon RG, Peskin MR:

Transpedicular lumbar wedge resection osteotomy for fixed sagittal imbalance: surgical technique and early results. Spine (Phila Pa 1976) 2006; 31: 485-492.

36. Yang BP, Ondra SL, Chen LA, et al: Clinical and radiographic outcomes of thoracic and lumbar pedicle subtraction osteotomy for fixed sagittal imbalance. J Neurosurg Spine 2006; 5: 9-17.

37. Buchowski JM, Bridwell KH, Lenke LG, et al: Neurologic complications of lumbar pedicle subtraction osteotomy: a 10-year assessment. Spine (Phila Pa 1976) 2007; 32: 2245-2252.

38. Ikenaga M, Shikata J, Takemoto M, Tanaka C: Clinical outcomes and complications after pedicle subtraction osteotomy for correction of thoracolumbar kyphosis. J Neurosurg Spine 2007; 6: 330-336.

39. Mummaneni PV, Dhall SS, Ondra SL, Mummaneni VP, Berven S: Pedicle subtraction osteotomy. Neurosurgery 2008; 63: 171-176.

40. Kiaer T, Gehrchen M: Transpedicular closed wedge osteotomy in ankylosing spondylitis: results of surgical treatment and prospective outcome analysis. in press. Eur Spine J 2009.

41. Kim YJ, Bridwell KH, Lenke LG, Cheh G, Baldus C: Results of lumbar pedicle subtraction osteotomies for fixed sagittal imbalance: a minimum 5-year follow-up study. Spine (Phila Pa 1976) 2007; 32: 2189-2197.
42. MacLennan A: Scoliosis. Br Med J 1922; 2: 865-866.

43. Boachie-Adjei O, Bradford DS: Vertebral column resection and arthrodesis for complex spinal deformities. J Spinal Disord 1991; 4: 193-202.

44. Bradford DS, Boachie-Adjei O: One-stage anterior and posterior hemivertebral resection and arthrodesis for congenital scoliosis. J Bone Joint Surg Am 1990; 72: 536-540.

45. Luque ER: Vertebral column transposition. Orthop Trans 1983; 7: 29.

46. Bradford DS: Vertebral column resection. Orthop Trans 1987; 11: 502

47. Suk SI, Kim JH, Kim WJ, et al: Posterior vertebral column resection for severe spinal deformities. Spine (Phila Pa 1976) 2002; 27: 2374-2382.

48. Bradford DS, Tribus CB: Vertebral column resection for the treatment of rigid coronal decompensation. Spine (Phila Pa 1976) 1997; 22: 1590-1599.

49. Suk SI, Chung ER, Lee SM, et al: Posterior vertebral column resection in fixed lumbosacral deformity. Spine (Phila Pa 1976) 2005; 30: E703- E710.

50. Suk SI, Chung ER, Kim JH, et al: Posterior vertebral column resection for severe rigid scoliosis. Spine (Phila Pa 1976) 2005; 30: 1682-1687.

51. Lenke LG, O'Leary PT, Bridwell KH, et al: Posterior vertebral column resection for severe pediatric deformity: minimum two-year follow-up of thirty-five consecutive patients. Spine (Phila Pa 1976) 2009; 34: 2213-2221. 